\section{CIVILTEC}

Revista Técnico-Científica

de Engenharia Civil
Volume $2-$ n. $2-2021$

http://periodicos.unesc.net/engcivil

\title{
Estudo do escoamento pluvial superficial na rua General Osvaldo Pinto da Veiga, Criciúma/SC
}

Doi: http://dx.doi.org/10.18616/civiltec.v2i2.6851

\author{
Maria Eugenia Maccarini ${ }^{1}$
}

Flávia Cauduro²

\section{Introduçã̃o}

Os alagamentos vem sendo problemas corriqueiros em vários centros urbanos. Sendo um empecilho decorrente da urbanização que tende a impermeabilizar o solo e acelerar o escoamento por condutos e canais. Este processo produz o aumento da vazão máxima e o aumento da velocidade do escoamento (TUCCI, 2012). A partir desse cenário, surge a importância de estudos para a implementação de sistemas alternativos de drenagem urbana, com o objetivo de reduzir os impactos e minimizar os danos causados pelas inundações. Dentre esses sistemas, destacam-se as técnicas compensatórias, que visam reduzir a vazão de pico, por meio de sua infiltração (BENINI, 2015). Os pavimentos permeáveis podem ser utilizados, especialmente em estacionamentos e ruas com tráfego leve, assim contribuindo para os sistemas de drenagem como uma maneira de amenizar o escoamento superficial (GARCIA, 2019). A utilização do pavimento permeável é um dos instrumentos que contribui para a drenagem das águas pluviais, amortecendo os picos de cheia e reduzindo o risco de enchentes. Além disso, reduz a lâmina d'água sobre o pavimento, aumentando a segurança do usuário e aumentando a área de infiltração da água (MARCHIONI e SILVA, 2011). Este trabalho propõe um estudo sobre o escoamento pluvial superficial de parte da rua General Osvaldo Pinto da Veiga, localizada na cidade de Criciúma, Santa Catarina.

\section{Metodologia}

A área de estudo abrange um trecho da rua com comprimento talvegue de 700 metros e com área de $61.000 \mathrm{~m}^{2}$, localizada no bairro Próspera, em Criciúma. Para análise e dimensionamento do sistema de drenagem, foram adotados dois cenários (tabela 1), sendo o cenário 1, correspondente à situação real/atual da via estudada, englobado o quantitativo e a tipologia das bocas de lobos existentes na rua, vistoriadas in loco. No cenário

\footnotetext{
1 Acadêmica, Universidade do Extremo Sul Catarinense, memaccarini@unesc.net

2 Mestre, Universidade do Extremo Sul Catarinense, flavia.cauduro@unesc.net
} 


\section{CIVILTEC}

Revista Técnico-Científica

de Engenharia Civil

\section{Volume $2-$ n. 2 - 2021}

http://periodicos.unesc.net/engcivil

2, utilizou-se o método de pavimentos permeáveis, que consistem em paver drenante. Aplicou-se essa estratégia de drenagem nos estacionamentos, nas faixas de rolamento da rua estudada e nos passeios públicos desta.

Tabela 1. Comparação dos Coeficientes. (Fonte: elaboração própria)

\begin{tabular}{llll}
\hline \multirow{2}{*}{ Região } & \multicolumn{2}{l}{ Área de Superfície } & C \\
& Cenário 1 (\%) & Cenário 2 (\%) & \\
Área construída (Telhado) & 42,41 & 42,41 & 0,95 \\
Rua c/ Asfalto & 18,00 & - & 0,95 \\
Rua c/ Paver & - & 18,00 & 0,50 \\
Gramado & 16,10 & 16,10 & 0,15 \\
Estacionamento c/ Lajota & 13,06 & - & 0,70 \\
Estacionamento c/ Paver & - & 13,06 & 0,50 \\
Passeio c/ Cerâmica & 10,42 & - & 0,95 \\
Passeio c/ Paver & - & 10,42 & 0,50 \\
\hline Coeficiente de Escoamento Pluvial Médio & 0,79 & 0,63 & - \\
\hline
\end{tabular}

Os dados planialtimétricos foram obtidos através do site SIGSC (2012). Foi adotado o período de retorno de 2 anos para os cenários (TOLEDO, 2017), o tempo de duração da chuva de 5 minutos, coeficientes de rugosidade e escoamento pluvial relacionados aos revestimentos e o fator de entupimento da boca de lobo foi considerado $80 \%$ e $60 \%$ para o tipo guia e grade, respectivamente.

A vazão máxima foi estimada com o Método Racional Modificado, e a vazão e velocidade de escoamento na sarjeta foram calculadas através da fórmula de Manning, modificada por Izzard (BACK, 2015).

\section{Resultados}

Através do diagnóstico técnico de campo, foram levantadas em toda a extensão do trecho estudado as seguintes condições: 3 bocas de lobo do tipo guia e 3 bocas de lobo do tipo grade, localizadas conforme figura 1. A situação atual apresentou problemas estruturais, dentre eles a incapacidade de as bocas de lobo captarem todo o escoamento das sarjetas. Estas falhas provocam pontos de alagamento que trazem riscos, tanto para as pessoas a pé quanto para os motoristas de automóveis que transitam no local, pois podem esconder buracos na pista, além de transmitirem doenças. 
CIVILTEC

Revista Técnico-Cientifica

de Engenharia Civil
Volume $2-$ n. $2-2021$

http://periodicos.unesc.net/engcivil

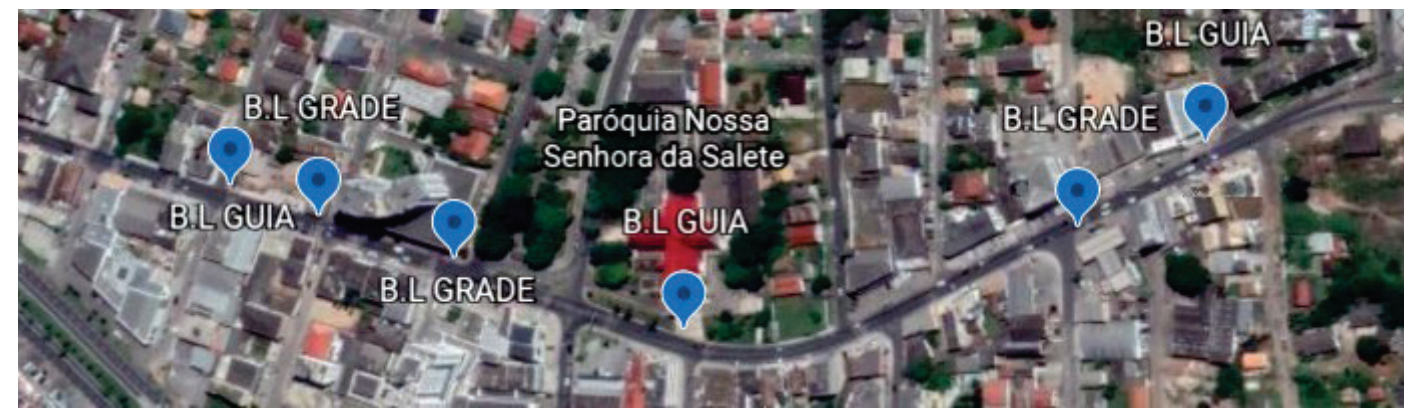

Figura 1. Localização das bocas de lobo no trecho da via estudada. (Fonte: Google Maps, 2021)

A origem desses problemas se deve ao número insuficiente de bocas de lobo, ao armazenamento de resíduos sólidos em algumas unidades, à baixa (ou inexistente) declividade presente na rua, e aos pontos de sarjeta rasa. A tabela 2 apresenta os parâmetros observados nos dimensionamentos dos modelos estudados.

Tabela 2. Comparativos dos resultados. (Fonte: elaboração própria)

\begin{tabular}{lll}
\hline Parâmetros & Cenário 1 & Cenário 2 \\
Coeficiente de escoamento pluvial médio & 0,79 & 0,63 \\
Vazão lançada no sistema $\left(\mathrm{m}^{3} \mathrm{~s}^{-1}\right)$ & 0,88 & 0,70 \\
Velocidade máxima de escoamento $\left(\mathrm{ms}^{-1}\right)$ & 2,5 & 1,5 \\
№ de B.L necessárias & 28 & 23 \\
\hline
\end{tabular}

A redução de $20 \%$ do coeficiente de escoamento pluvial entre a condição atual da via e a condição modificada promoveu uma redução em torno de $20 \%$ na vazão lançada no sistema e a diminuição de 5 bocas de lobos no trecho. Houve a redução de $40 \%$ da velocidade máxima de escoamento. A rugosidade do pavimento permeável irá contribuir para a sedimentação dos sólidos na sarjeta e para reduzir o deflúvio na via.

\section{Conclusão}

A drenagem do trecho estudado mostrou, atualmente, não comportar a vazão escoada desta superfície. Em diagnóstico técnico de campo e, posteriormente, a partir do dimensionamento, foi constatado que não há padrão do tipo ou formato das bocas de lobo. A quantidade de bocas de lobo é insuficiente, com apenas 6 unidades existentes, e, conforme o dimensionamento, há necessidade de 28 bocas de lobo. Outros problemas observados foram a falta de manutenção e limpeza e a declividade insuficiente ou inexistente para o fluxo pluvial em determinados locais. 


\section{CIVILTEC}

Revista Técnico-Cientifica

de Engenharia Civil

\section{Volume 2 - n. 2 - 2021}

http://periodicos.unesc.net/engcivil

O sistema alternativo de drenagem mostrou-se eficaz na redução do escoamento, pois reduziu $20 \%$ do valor de coeficiente de escoamento pluvial e da vazão de drenagem, 5 unidades de bocas de lobo e $40 \%$ da velocidade de escoamento.

Palavras-chave: Alagamento. Manejo Pluvial. Pavimento Permeável. Drenagem Urbana.

\section{Referências}

BACK, A. J. Hidráulica e hidrometria aplicada (com programa HidroChusc para cálculos). Florianópolis: EPAGRI, 2015.

BENINI, S. M. Infraestrutura verde como prática sustentável para subsidiar a elaboração de planos de drenagem urbana: estudo de caso da cidade de Tupã/ SP. Tese (Doutorado em Geografia) - Universidade Estadual Paulista Júlio Mesquita Filho. Presidente Prudente, 2015.

GARCIA, J. M. C. Análise da utilização de peças de concreto permeável em estacionamentos na redução de escoamento superficial. 2019. 70 f. TCC (Graduação em Engenharia Civil) - Centro Universitário Luterano de Palmas (CEULP/ULBRA). Tocantins, 2019.

MARCHIONI, M; SILVA, C. O. Pavimento Intertravado Permeável - Melhores práticas. São Paulo: Associação Brasileira de Cimento Portland (ABCP), 2011.

SANTA CATARINA. Sistema de Informações Geográficas - SIGSC. Levantamento Aerofotogramétrico. Publicado em 2012. Disponível em: <http://sigsc.sds.sc.gov.br/>. Acesso em: 10 set. 2021.

TOLEDO (cidade). Secretaria Municipal de Desenvolvimento Urbano. Manual de drenagem urbana. Paraná, 2017.

TUCCI, C. E. M. Gestão da drenagem urbana. Brasília: CEPAL/IPEA, 2012. 50 p. 